revista ANTHROPOLÓGICAS

Ano 24, 31(1): 141-168, 2020

\title{
Plantando Mandioca e Criando In/comensurabilidades
}

Gabriel Graton Roman ${ }^{a}$ Iara Maria de Almeida Souza ${ }^{\mathrm{b}}$

O presente artigo examina a forma como a mandioca é plantada na comunidade quilombola Espírito Santo do Itá (PA) a fim de identificar momentos de conflito e negociações entre o saber tradicional, materializado na prática de cultivo local, e o saber técnico-científico, presente principalmente em cursos técnicos municipais oferecidos para os produtores da comunidade. As práticas de plantio de mandioca são examinadas seguindo uma abordagem semiótica material, extrapolando, assim, uma discussão puramente epistemológica, tornando o saber uma questão também ontológica. Nos momentos etnográficos explorados, foram identificadas três estratégias utilizadas na comunidade que contribuíram para a coexistência do saber local frente um saber técnico-científico divergente: 1 . A realização de comparações no campo material e corporificado; 2 . O controle dos critérios relevantes para a comparações; e 3. A criação de incomensurabilidades. Dessa forma, sugerimos que a negociação entre saberes divergentes na comunidade é marcada por articulações de padrões de in/comensurabilidade.

Semiótica material,Saber local, Práticas desaber, Comensurabilidade, Quilombola.

Como se planta mandioca? Sr. Aleontino explica que "[...] tem que plantar duas manivas, pé com ponta". Assim como muitos mo-

a Mestre em Estudos Internacionais do Desenvolvimento, Norwegian University of Life Science (NMBU). Email: gabrielgroman1@gmail.com.

b Professora do Departamento de Sociologia da Universidade Federal da Bahia. Email: imas@ufba.br. 
radores da comunidade quilombola de Espírito Santo do Itá (PA), Sr. Aleontino trabalhou com mandioca a vida inteira. Ele aprendeu sobre esse plantio com seus pais, ensinou seus filhos, e eles ensinaram seus netos. Esse saber compartilhado, no entanto, coexiste com um conhecimento técnico-científico que, entre outras vias, chega à comunidade por meio de cursos e palestras frequentados por alguns dos seus membros.

Este artigo busca explorar alguns momentos de negociação que se dão quando práticas de saber tradicionais são confrontadas com um conhecimento técnico-científico divergente. A comunidade quilombola Espírito Santo do Itá é o palco no qual se dão os confrontos abordados aqui, que giram em torno da forma como a mandioca é plantada por seus moradores. O saber tradicional contrasta por vezes com as recomendações técnico-cientificas que têm sido difundidas no local. O propósito deste artigo é justamente examinar algumas das maneiras como essas divergências são negociadas e resolvidas.

\section{A comunidade Espírito Santo do Itá}

A comunidade quilombola Espírito Santo do Itá está localizada no nordeste do Estado do Pará, no município de Santa Izabel. A distância da comunidade para a sede municipal, a cidade de Santa Izabel do Pará, é de $20 \mathrm{~km}$, e $45 \mathrm{~km}$ a separam de Belém, a capital do estado. Para chegar a ela, o meio de transporte mais usado é a van, mas também é possível transitar até lá de moto, carro, ou ônibus escolar. A sede municipal é a cidade mais próxima para realizar compras, ir ao banco, ir à escola (depois do ensino fundamental) ou vender os produtos produzidos na feira.

A estrada que liga Santa Izabel do Pará à comunidade, é asfaltada, mas está em péssimo estado de conservação, de modo que para chegar de um lugar a outro o transporte segue com muita lentidão. No caminho é possível observar a existência, em um lado da pista, de grandes propriedades de terra cercadas, utilizadas para criação de gado. Ainda na rodovia, está localizada a Unidade de Saúde que atende as comu- 
nidades da região. Dali, é necessário seguir três quilômetros em uma estrada de terra para chegar a Espírito Santo do Itá. Essa estrada também leva a Americano, uma outra localidade do município, conhecida pela venda da farinha de tapioca.

No território da comunidade, além da casa dos moradores (onde vivem em torno de 45 famílias), existem duas igrejas (católica e protestante), um galpão para eventos (principalmente o Festival da Mandioca) e 9 casas de farinha. Apesar do acesso um pouco difícil e da falta de uma conexão com a internet, a comunidade parece ter um contato próximo com outras cidades do município e estado. Isso se deve à participação na feira da cidade de Santa Izabel, à relação próxima da comunidade com a Secretaria de Agricultura da prefeitura, e, mais recentemente, ao Festival da Mandioca, que ocorre anualmente desde 2012. Diversos membros da comunidade também recebem auxílios governamentais, desde programas como Bolsa Família, até o Programa Fomento Rural (fornecido pela EMATER), que consiste em transferências não-reembolsáveis para fins produtivos, utilizado para a construção de casas de farinha e compra de equipamentos. Além disso, parece existir uma relação de parceria entre as diferentes comunidades formadas às margens do rio Itá (muitas das quais são quilombola), marcada por visitas, bingo, festas, e jogos de futebol.

Assim como nestas outras comunidades, a atividade econômica principal dos moradores é a venda dos produtos da mandioca: farinha, tucupi, goma e, em menor quantidade, maniçoba. $\mathrm{O}$ processamento da mandioca, apesar de ter sofrido algumas mudanças, já é uma atividade histórica no Espírito Santo do Itá, atravessando diversas gerações. Esse processo inclui várias etapas, desde a plantação da maniva, até a torração da farinha e o cozimento do tucupi. Essas atividades são realizadas nas 9 casas de farinha da comunidade, todas propriedades individuais ${ }^{1}$, mas cujo uso é coletivo, compartilhado entre familiares e amigos, sem que um valor seja cobrado pelos usos desse espaço e instrumentos. ${ }^{2}$ É importante destacar, no entanto, que alguns membros da comunidade optam por trabalhar em empregos 
assalariados nas cidades próximas, como, por exemplo, em fábricas. Além disso, a coleta de frutos, pesca, e as vezes caça, também podem ser realizadas para a obtenção de alimentos.

As terras para plantação são propriedades individuais de membros, cuja transmissão é feita na forma de herança. No entanto, alguns moradores nas últimas décadas decidiram vender seus lotes, reduzindo o espaço destinado à plantação. Atualmente, um fazendeiro e empreendedor é dono de grande parte da área que pertencia anteriormente à comunidade. Restam apenas 5 terrenos (de 15 hectares cada), apropriados individualmente por membros da comunidade e documentados. $O$ uso desses terrenos é, no entanto, coletivo, sendo cada um compartilhado por 3 ou 4 famílias. A maior parte da terra é utilizada somente para a plantação da mandioca, mas alguns moradores também produzem melancia, macaxeira, ou outros cultivos em pequena escala, para consumo próprio.

Esse espaço limitado para plantação se tornou ainda mais problemático com a recente redução na produtividade do solo e aumento na demanda dos produtos, tornando inviável que as famílias dependam somente da produção interna da mandioca. Assim, nessa última década, pessoas passaram a se organizar para comprar mandioca de outros produtores, realizando somente a colheita e o processamento das raízes e folhas. Nesse caso, eles se deslocam para os terrenos onde estão as plantas, algumas vezes com o transporte subsidiado pela prefeitura, colhem a mandioca e retornam para as casas de farinha para realizar o processamento. As roças da comunidade continuam a ser cultivadas por algumas famílias, mas se tornaram apenas uma fonte secundária para a produção de farinha e outros derivados da mandioca.

Para entendermos mais facilmente essa organização produtiva, é relevante pensarmos em duas categorias: os donos da mandioca e os trabalhadores. Esse primeiro grupo compra a mandioca dos produtores, contrata outros membros da comunidade para realizar a co- 
lheita ou outras etapas do processamento, e contata com os clientes (tanto aqueles a quem vendem na feira quanto os que realizam encomendas). O segundo grupo, no entanto, trabalha para os donos da mandioca, principalmente em troca de um pagamento (definido ou variável). Além disso, também são trabalhadores os familiares dos donos da mandioca cujo serviço é considerado como 'ajuda', e não é diretamente remunerado (normalmente o trabalho não remunerado é realizado por mulheres, filhos e idosos).

O que define o dono da mandioca ${ }^{3}$, aquele que se vale do trabalho assalariado de outros membros da comunidade, não é a posse de terra ou não, ou da casa de farinha, já que o uso desses meios de produção é coletivo. Muitos donos de mandioca, inclusive, não são donos nem de uma, nem da outra onde trabalham. Dessa forma, as categorias que organizam essa produção não são fixas, sendo necessário somente estabelecimento de vínculos com clientes para se tornar um dono de mandioca. Uma moradora da comunidade, Cacá, era anteriormente uma trabalhadora (não diretamente remunerada) que 'ajudava' seu marido (dono de mandioca). Para adquirir seu próprio dinheiro, ela passou a colher mandioca pra si mesma e conseguir clientes para seus produtos, se tornando assim uma dona de mandioca.

A venda dos produtos ocorre, em sua maior parte, através de encomendas de clientes fixos, tanto pequenos mercados e restaurantes, quanto consumidores. Os produtos são, então, entregues diretamente aos compradores, utilizando a moto ou a linha da van. Aos sábados, alguns donos de mandioca também levam seus produtos para serem vendidos na feira da cidade de Santa Izabel do Pará, onde clientes novos podem ser atraídos. Desde que o Festival da Mandioca passou a ser realizado, esse evento se tornou uma grande fonte de renda coletiva.

Como mencionado, a plantação e processamento da mandioca são atividades tradicionais na comunidade e, portanto, não se guiam por padrões técnico-científicos. As divergências entre as diferentes práticas de conhecimento só se tornam visíveis nos pontos de interação 
entre elas. Há duas formas principais de entrada do conhecimento técnico-científico na comunidade: 1 . Através de projetos da prefeitura, como cursos e palestras que a comunidade é convidada a participar, muitas vezes proporcionando a interação com produtores industriais de farinha; 2. Através do aprendizado da geração mais jovem, que realiza cursos formativos nas cidades vizinhas e, portanto, interagem com esse saber diferente. É possível adicionar uma terceira entrada, a do Festival da Mandioca, que por receber visitas de pessoas de outros lugares, até estrangeiros, requer algumas mudanças na apresentação da produção que ocorre na casa de farinha (i.e., o uso de luvas plásticas e toucas), no entanto como o foco deste artigo é na plantação, essa terceira entrada não foi incluída.

Em conversas, a divergência é descrita pelos membros da comunidade como 'a forma como a gente planta' e 'a forma como eles plantam'. O conhecimento técnico-científico, portanto, não é normalmente conectado com pessoas ou comportamentos específicos, mas existe uma fronteira comumente conhecida pelos moradores que marca essa diferença. Além disso, as pessoas da comunidade têm grande autonomia para decidir a forma como plantam as raízes e produzem a farinha. Ainda assim, é possível identificar uma posição adotada por alguns membros do grupo, depois da realização de cursos oferecidos pela prefeitura visando trazer o conhecimento técnico para a comunidade, de que, entre outros benefícios, a aplicação desse conhecimento pode aumentar a produtividade do solo e, portanto, a produção dos derivados da mandioca.

A forma como práticas tecnocientíficas convivem com outras práticas de conhecimento é uma temática comum em muitos estudos sobre ciência. Crucial para abordar esse ponto é ter clareza sobre o modo de enquadrar a questão, que facilmente poderia cair em dois caminhos opostos, um deles envolve a busca por apontar qual conhecimento é mais verdadeiro, no sentido de que representa melhor a realidade objetiva e o mundo natural, ou, por outro lado, poderia levar a uma atitude relativista que trata toda forma de representação 
do mundo como equivalente e desconsidera qualquer reivindicação de veracidade ou da existência de um mundo fora da linguagem. $\mathrm{O}$ problema com essa posição é que ela conduz a um esvaziamento de realidades que são decisivas para os praticantes, seja os da ciência ou de outras formas de conhecimento. O problema com a primeira atitude é a tendência a tomar a ciência ocidental como o parâmetro a partir do qual outras práticas serão comparadas e, portanto, colocadas em uma situação de desvantagem.

O saber técnico-científico, seguindo uma linha histórica a partir da ciência moderna, apresenta uma forte ambição à universalidade, utilizando o 'truque de Deus' (Haraway 1995) e impondo assim uma homogeneização prepotente, que destrói a diversidade de práticas de conhecimento tradicionais (Stengers 2011). É nesse contexto que precisamos entender essas negociações entre saberes. É possivel observar em Espírito Santo do Itá uma coexistência de saberes contraditórios, através da qual a heterogeneidade é preservada? De que forma os membros da comunidade resistem a incorporação total da lógica técnico-científica e a destruição de seu conhecimento tradicional? Este artigo se propõe experimentar com algumas respostas para essas perguntas, inspirado pela perspectiva de uma possível 'ecologia de práticas' (Stengers 2005), cujo primeiro passo é: "a exigência de que nenhuma prática seja definida 'como qualquer outra', assim como nenhuma espécie viva é como qualquer outra." (Stengers 2005:184 - tradução nossa).

Para realizar essa proposta, no entanto, é necessário extrapolar o campo puramente epistemológico, não se restringindo, assim, a discussões sobre interpretações culturais de fatos dados como 'naturais' e 'universais' (Latour 1993). Seguindo o movimento da 'virada ontológica' na Antropologia (i.e., Holbraad \& Pedersen 2017; Kohn 2007) e no campo interdisciplinar de Ciência, Tecnologia e Sociedade (CTS) (i.e., Law \& Lien 2013; Mol 2013), pretendemos deixar de lado a divisão moderna de natureza/cultura, optando assim por uma abordagem performativa e semiótica material. 


\section{As sensibilidades da semiótica material}

Semiótica material é definida por Law (2019) como:

"[...] um movimento na ciência social que cultiva um conjunto de sensibilidades para a prática, para processo, para os emaranhados de materialidade e narrativa, para o caráter irremediavelmente situado desses emaranhados (incluindo o seu próprio), para a diferença, e para a ideia de que não há uma lógica única por trás das complexidades do social” (Law 2019:15 - tradução nossa).

Esse termo, portanto, engloba múltiplos estudos, na sua maioria de cunho empírico, que tem rejeitado os dualismos modernos de natureza/cultura e material/discursivo. Algumas de suas abordagens são a Teoria Ator-Rede (TAR) (i.e., Latour 2005; Callon 1980; 1984; Law 1986), a semiótica material feminista (i.e., Haraway 1995; Barad 2017), e, mais recentemente, o que tem sido chamado de Pós-TAR (i.e., Mol 2002; ver também Gad \& Jensen 2010).

Apesar desse movimento ser diverso, acreditamos que existam alguns compromissos teóricos em comum. Primeiramente, esses estudos se interessam por práticas de construção-de-mundo, através das quais entidades passam a existir simbolicamente e materialmente em suas relações (Law 2019). Desta forma, a existência de entidades (humanos e não-humanos) não é tida como anterior às práticas (Haraway 2003; Barad 2007), ou presente fora de redes heterogêneas de humanos e não-humanos (Latour 1996). Essa é uma posição fortemente anti-essencialista, já que existe uma rejeição de definições e categorizações de entidades a priori (i.e., natureza/cultura, humano/não-humano), apresentando, ao invés disso, uma 'ontologia plana' (Latour 1987; Law 2019; Haraway 1991).

Este trabalho é também inspirado pelo recente movimento nas Humanidades chamado de 'virada ontológica', definida por Woolgar \& Lezaun como: "[...] um esforço para contornar a epistemologia e sua linguagem de representação em favor de uma abordagem que se dirija mais diretamente à composição do mundo" ${ }^{5}$ (2013:322 - tradu- 
ção nossa). Apesar de ser um título que ainda gera debates (i.e., Holbraad, Pedersen \& Viveiros de Castro 2014; Woolgar \& Lezaun 2013, 2015; Van Heur et al. 2013; Aspers 2015), e da preocupação com o ontológico não ser apenas recente, estando presente em trabalhos de semiótica material desde os anos 80 (i.e. Latour \& Woolgar 1986; Haraway 1991; Cussins 1996; Star \& Greisemer 1989), acreditamos que esse movimento traz ferramentas interessantes para desestabilizar os dualismos da modernidade.

Por fim, localizamos este trabalho na área de intersecção entre a antropologia e CTS. Acreditamos que esse é um terreno fértil, recentemente explorado por pesquisadores interdisciplinares (i.e. Jensen \& Rödje 2010; Jensen \& Morita 2019; Omura et al. 2018), e que pode contribuir com discussões sobre práticas de saber e performances. No próximo segmento, apresentaremos o campo no qual desenvolvemos esta pesquisa e algumas questões metodológicas.

\section{Questões de método}

Como explicado acima, a pesquisa que embasa este trabalho foi realizada na comunidade quilombola Espírito Santo do Itá, no município de Santa Izabel (PA). Durante quatro semanas de outubro de 2019 um de nós, Gabriel, permaneceu na comunidade e lá fez observação de práticas e entrevistas com membros específicos da comunidade. ${ }^{6}$ Não se trata, portanto, de um trabalho etnográfico com pretensões totalizantes, mas uma aproximação que, embora seja parcial, permitiu a exploração de questões relativas ao cultivo da mandioca.

Também não é o objetivo deste artigo descrever de maneira geral o conhecimento tradicional da comunidade sobre o plantio da mandioca. A questão que interessa aqui é refletir sobre a relação entre o saber dos quilombolas e o saber técnico-científico e isso será explorado a partir de alguns momentos etnográficos observados durante o trabalho de campo. 
Antes de apresentá-los, entretanto, acredito ser necessário explicitar o caráter situado deste conhecimento aqui produzido. Donna Haraway desenvolveu uma versão de objetividade feminista calcada na ideia de saberes situados, como explicado:

"[...] a objetividade revela-se como algo que diz respeito à corporificação específica e particular e não, definitivamente, como algo a respeito da falsa visão que promete transcendência de todos os limites e responsabilidades. A moral é simples: apenas a perspectiva parcial promete visão objetiva" (Haraway 1995:21).

Essa localização dos saberes indica uma não inocência, sendo oposta, então, a epistemologias positivistas e relativistas que prometem "[...] visão de toda parte e de nenhum lugar" (Haraway 1995:24).

Esse conceito de objetividade feminista proposta por Haraway foi amplamente adotado por autores que tentam superar alguns problemas de reflexividade na produção de conhecimento. No entanto, como Karen Barad alerta, saberes situados são, muitas vezes, confundidos com uma ideia de 'posição social'. Barad ressalta que esse conceito não diz respeito a uma localização fixa e sim uma 'conexão específica' (Barad 2007:471). Ela argumenta ainda que: "[o]s saberes situados não se limitam apenas a conhecer/ver a partir de algum lugar (como em perspectiva), mas de levar em conta como a corporificação protética específica do dispositivo de visualização tecnologicamente aprimorado é importante para as práticas de conhecimento" (Barad 2014:238 - tradução nossa).

Pretendemos, portanto, deixar explícita a criação dessa narrativa apresentada como um resultado de um emaranhado, do qual fazem parte tanto nós, pesquisadores, quanto os membros da comunidade, os nossos instrumentos teóricos, os dispositivos de visualização e a própria mandioca. Isso diz respeito à contingência de nossa análise e a uma apreciação pela participação dessas entidades nessa performance textual. Isso não absolve, no entanto, nossas responsabilidades por esse conhecimento, mas aceita a posição não-inocente necessária nessa atividade de pesquisa. 


\section{História de quilombos e mandioca}

Comunidades quilombola e a mandioca apresentam uma relação histórica importante no Brasil. A farinha produzida a partir da mandioca foi o principal alimento para as populações escravizadas, inclusive nos navios negreiros (Cascudo 2011; Modesto Júnior \& Alves 2015). Em seu estudo sobre os hábitos alimentares de pessoas escravizadas no estado do Pará no século XIX, Neto \& Macêdo afirmam que:

"A farinha de mandioca era tão importante que escravos fugidos, em trânsito ou sem pouso certo, ou que não tinham como fazer suas próprias roças de mandioca, tinham que se valer de sua astúcia e da cumplicidade com outros sujeitos a fim de obter a farinha. Situação distinta era a dos escravos fugitivos vivendo em quilombos, que além da caça, da pesca, da coleta dos frutos da floresta, tinham as suas próprias roças, entre elas a de mandioca para a produção não só dos diversos tipos de farinha, mas também do tucupi" (Neto \& Macêdo 2009:4-5).

Essa posição de destaque dada para a mandioca em quilombos é de tamanha importância que historiadores e arqueólogos como João Reis, por exemplo, estabelecem em suas especulações uma relação entre tamanho das plantações de mandiocas em quilombos e a quantidade de moradores (Gomes 2015). Atualmente, a mandioca continua a ser plantada e processada em muitas das comunidades remanescentes de quilombo (i.e. Costa 2010; 2012; O’Dwyer \& Carvalho 2002; Oliveira 2002; Pedroso Junior et al. 2008; Vizolli et al. 2012), incluindo, como já dito, Espírito Santo do Itá.

Nessa comunidade, no entanto, tem-se observado, como explicado acima, uma mudança na forma como a mandioca é obtida. Nos últimos anos, a maior parte das raízes processadas tem sido comprada de outros produtores da região, ao invés de serem plantadas pelos próprios membros. Isso se deve tanto ao aumento da demanda do mercado consumidor, que passou a não ser suprida somente com a mandioca produzida nas terras da comunidade, quanto a uma redução na produtividade do solo. Cristina, a Presidente de Espírito Santo do Itá explica que: 
[...] [a gente] compra é porque aumentou nossa produção, a venda. Também por causa que nossa área de terra não tá boa pra produzir a mandioca. [...] Se eu pudesse, eu fazia mais isso [plantar] do que comprar, porque rende mais né, dá mais lucro. [...] [mas] a gente se acostumamos a comprar e achamos mais fácil né... e a terra também não tá produzindo bacana [...] as vezes ela morre antes de estar pronta pra colheita, não dá bem a batata [...]. (Cristina, em entrevista).

Essa mudança na forma de aquisição da mandioca tem também, como uma de suas consequências, uma redução no interesse da população mais jovem em aprender a forma tradicional de plantar a mandioca. Sr. Aleontino, um dos mais velhos da comunidade, em uma entrevista, afirmou que muitos dos jovens não sabem como plantar mandioca corretamente. $\mathrm{O}$ mesmo foi dito por sua filha, Maria, que também realiza o cultivo dessa raiz. Essa moradora será nossa guia no próximo segmento desse artigo, no qual pretendemos apresentar algumas das características da forma tradicional de plantar a mandioca na comunidade, que foram observadas durante o trabalho de campo.

\section{Plantando mandioca em Espírito Santo do Itá}

Como já explicado, o cultivo da mandioca deixou de ser a maneira mais prevalente de obter a raiz na comunidade e, portanto, as oportunidades para observar essa prática foram reduzidas. No entanto, após uma conversa com Maria, ela concordou em apresentar seu trabalho na plantação. Seu pai é dono de um dos lotes de terra, e ela e seus filhos cultivam mandioca em algumas roças ali. Por não ser a época em que a comunidade realiza o plantio, foi observado, então, o 'replantio' dos pés de mandioca que não brotaram.

Para chegar até as terras onde a comunidade realiza seu plantio, foi necessário andar em torno de 15 minutos. O motivo dessa distância é que os antigos moradores, que eram donos desses primeiros lotes de terra, os venderam para um grande proprietário, que agora tem a posse de uma faixa do terreno que separa a comunidade da roça onde trabalham.

Ao chegar no lugar de cultivo, Maria me mostrou uma roça na qual 
as plantas de mandioca ainda eram bem pequenas. Ela explicou que elas tinham apenas 2 meses. Para mim foi difícil andar entre os brotos, já que era necessário atenção e equilíbrio para não pisar em nenhuma planta.

Usando uma enxada, ela me mostrou como capinar, demonstrando o cuidado necessário para não 'quebrar o pé da maniva'. Com movimentos fortes da enxada, são apenas retiradas as plantas não desejadas e, assim, a roça é limpa.

Após capinar grande parte do lote, Maria pegou seu terçado (facão) e se aproximou de um apoio improvisado construído com 3 pedaços de madeira. Ela trouxe, então, cerca de 10 pedaços grandes de ramas que haviam sido cortadas de seus cultivos anteriores, e que agora seriam plantados. Usando o terçado, Maria cortou rapidamente as ramas em pequenos pedaços, cada um contendo cerca de 4 a 7 gemas. Esses pedaços são chamados de maniva, e estão prontos para ser plantados caso tenham sido cortados corretamente, com golpes fortes e limpos.

Usando a enxada, ela cavou alguns buracos nos locais onde as manivas não tinham brotado. Quando perguntei o motivo de não terem crescido, explicou que a maniva ou o solo podem não ser bom, ou animais que vivem na mata ao redor, por exemplo um aracuã, podem ter comido o broto.

Os buracos foram cavados com uma distância entre eles de cerca de trinta centímetros e dentro deles foram colocadas duas manivas, na posição horizontal. Maria explicou que de um lado da maniva brota a raiz, e, do outro, o caule. Portanto, essas manivas devem ser colocadas 'pé com ponta', para que, assim, as raízes nasçam em lado opostos e não tenham que competir por espaço.

Depois das manivas serem corretamente posicionadas, Maria adicionou um punhado de fertilizante aos buracos. Ela explicou que o solo é antigo, e que tem sido usado por muitas gerações. Portanto, tornou-se necessário o uso de fertilizantes para alcançar a produtividade que os cultivos tinham anteriormente.

Utilizando a enxada, ou a própria sola do sapato, os buracos foram cobertos com terra. Após terminado esse processo na roça, Maria me disse que queria mostrar outra parte importante da plantação de mandioca: a preparação da terra. Ela me levou para outra roça, onde seus dois filhos, Ney e Eré, estavam realizando uma tarefa chamada 'encoivarar', que consiste na junção de galhos e troncos que sobraram na roça após uma primeira queima, para que sejam queimados novamente. 
Maria explicou que existem duas formas de preparar a terra: ou eles plantam 'no meio dos tocos', através da prática tradicional de corte-e-queima; ou, um trator do município é chamado para 'triturar' a terra, para que então o plantio possa ser realizado. Na primeira roça onde ela me mostrou como plantar a mandioca, a terra havia sido triturada, já nesta, onde seus filhos estavam encoivarando, era só 'no meio dos tocos'.

Após os galhos queimarem, Ney e Maria me levaram para outra roça onde as manivas haviam sido plantadas há cerca de 1 ano, e já estavam sendo colhidas aos poucos. Ela explicou que quando a mandioca é arrancada e as raízes estão saudáveis e grandes, ela separa as ramas para que sejam, então, plantadas.

Diversas entidades se fizeram presente nessa observação etnográfica. Além dos membros da comunidade, como Maria e seus filhos, a mandioca, animais selvagens, fertilizante, terçado, manivas, trator, e outros não-humanos também se mostraram importantes nessa performance.

A seguir, iremos identificar momentos de divergência entre algumas características dessa prática e as recomendações baseadas no conhecimento técnico-científico e como tais contradições são reconhecidas e resolvidas.

\section{Criando in/comensurabilidades}

Baseado nas observações realizadas, acreditamos que existam algumas diferenças entre a forma como a mandioca é plantada tradicionalmente na comunidade e como esse processo é tratado em livros técnicos e manuais. Para explorar esse tema, determinados momentos dessas duas práticas de saber serão contrastados. Dois pontos precisam ser destacados quanto à essa tentativa de contraste: (1) os termos 'práticas de conhecimento/saber' (cientifico ou tradicional) são usados aqui apenas de maneira heurística e não existem como totalidades homogêneas e abstratas. Tratam-se, ao contrário, de múltiplas práticas específicas, localizadas e heterogêneas que permitem ser agrupadas da forma realizada aqui apenas através de simplificações. Esse agrupa- 
mento e consequente simplificação é, no entanto, justificável uma vez que (2) essa distinção exista como uma categoria discursiva que habita as conversas entre os moradores da comunidade (i.e.: 'a forma como a gente planta e 'a forma como eles plantam'), não configurando, dessa forma, meramente uma imposição externa.

A questão aqui discutida não é, no entanto, a diferença entre práticas classificadas em categorias heurísticas distintas (sejam elas nossas ou dos moradores), mas como as contradições engendradas por essas diferenças são resolvidas dentro da comunidade. Para entender esse processo, os textos técnicos apresentados a seguir devem ser lidos como análises de práticas de conhecimento específicas, não como parte de um levantamento bibliográfico extensivo. Da mesma forma, cada segmento deste artigo apresenta momentos etnográficos particulares observados na comunidade, sem que exista a pretensão de obter uma narrativa única ao fim da descrição. Os trechos abaixo apresentam, no entanto, conexões parciais, que serão exploradas ao fim do artigo.

\section{Manivas e dispositivos de medição}

A primeira contradição entre essas práticas de saber que gostaríamos de abordar diz respeito às medições. Qual o tamanho recomendado das manivas na literatura técnica? Não parece existir uma resposta única, no entanto textos brasileiros recomendam em geral manivas de $20 \mathrm{~cm}$, com 5-7 gemas, e com uma grossura de $2 \mathrm{~cm}$ (Mattos, Farias \& Ferrreira Filho 2006; Dantas et al. 1981). Diferentes países, no entanto, apresentam diversas respostas:

"Os ameríndios no Brasil usam estacas de 50 a $60 \mathrm{~cm}$ de comprimento em sistemas de cultivo não mecanizados, mas, no mesmo país, fazendas modernas e mecanizadas usam estacas de 15 a $20 \mathrm{~cm}$ em plantadeiras mecânicas. $\mathrm{O}$ comprimento da maniva mais adequado é de 15 a $20 \mathrm{~cm}$ na Tailândia, 20 a $25 \mathrm{~cm}$ na Malásia, 25 a $30 \mathrm{~cm}$ na Índia e manivas curtas são recomendadas nas Filipinas para plantio horizontal e manivas mais longas para plantio vertical" (Lebot 2009:52 - tradução nossa). 
Além disso, a posição na qual as manivas são plantadas (Viana et al. 2000) e a forma de preparação do solo (Furlaneto et al. 2007) parecem influenciar seu tamanho ideal.

Quando contrastada com essas recomendações, as práticas performadas na comunidade apresenta um traço importante: as manivas usadas por Maria não têm $20 \mathrm{~cm}, 30 \mathrm{~cm}$, ou $10 \mathrm{~cm}$; o sistema métrico não faz parte dessa performance. Haraway, em diálogo com Barad, explica que: "[t]odas as medições dependem de escolhas corporificadas de dispositivos, condições para definir e incluir algumas variáveis e excluir outras e práticas históricas de interpretação" (2007:116 tradução nossa). O ponto principal que desejamos ressaltar aqui é que, quando examinamos práticas como performances semiótica-materiais, para plantar manivas de $20 \mathrm{~cm}$, um dispositivo de medição é necessário e sem ele, uma maniva não pode ser definida com um determinado valor do sistema métrico.

Utilizamos o termo 'dispositivo' aqui inspirados pela apropriação de Barad da palavra. Como explica a autora: "[...] dispositivos não são meros mecanismos estáticos no mundo, dispositivos são (re)configurações dinâmicas do mundo, práticas agenciais específicas/intra-ações/ performances pelas quais fronteiras excludentes específicas são operadas." (2017:21). Qual é, então, o dispositivo de medição utilizado por Maria? É seu conhecimento, visão, corpo e medidas alternativas de comprimento, como o número de gemas (que também está presente na literatura científica) e 'palmos'. Essas entidades formam seu dispositivo de medição que lhe permite, assim, diferenciar entre as manivas 'boas o suficiente' para serem plantadas e as que devem ser descartadas (por serem muito curtas, muito longas, ou não cortadas em um ângulo reto, por exemplo).

Seguindo essa interpretação, rejeitamos o uso do sistema métrico nesta observação etnográfica. Primeiramente, porque essa medição não é feita quando o processo de seleção de manivas é realizado por Maria, e, desse modo, fazê-la presente nesta narrativa seria equivalente à imposição de uma metalinguagem do pesquisador (Latour 2005). 
Em segundo lugar, realizar essa atividade impediria que o processo semiótico-material de medição, próprio dos atores estudados, fizesse parte da análise. Portanto, por uma consequência teórica e metodológica, decidimos não tornar invisível esse processo.

Essas observações levam, ainda, a uma reflexão sobre os textos técnico-científicos consultados: parece que, por utilizarem o sistema métrico, tais textos conseguem fazer os dispositivos de medição desaparecerem de suas narrativas (não existe necessidade de explicar como as manivas foram medidas: i.e., por quem, quando, utilizando qual instrumento...). Essas medidas, apesar de dependerem de uma rede heterogênea de humanos e não-humanos, são abstraídas de seu contexto de produção e perdem sua corporificação. Medições são sempre locais (Barad 2007), mas nesses textos, elas escondem sua materialidade (dispositivo - 'corpo'), se tornando, assim, 'abstratas'. Essa observação é inspirada pela análise sobre a construção de fatos científicos, desenvolvida por Latour e Woolgar (Latour 1987; Latour \& Woolgar 1986). Esses autores afirmam que fatos se tornam estabilizados conforme suas condições de produção (materialidade) desaparecem. A ênfase aqui é, no entanto, na desincorporação e abstração de medições, não na obtenção de uma estabilidade.

\section{Covas e conversões}

No caso apresentado acima, foram exploradas algumas das consequências das redes nas quais as práticas de saber contrastadas estão calcadas. Porém, uma pergunta importante permanece: como é possível, então, que os tamanhos das manivas nas diferentes práticas de saber sejam comparados, pelos membros da comunidade, se os dispositivos de medição são distintos? Uma conversão, ou tradução, é necessária para que essas medições se tornem comensuráveis. Este segundo episódio exemplifica essa operação.

Uma situação similar ao tamanho da maniva é o espaço que separa cada cova onde a mandioca é plantada. Apesar desse número também variar, a recomendação é de espaçamentos de em torno de 
1 metro x 50/60 cm (Mattos, Farias \& Ferrreira Filho 2006). Além disso, plantações muito próximas são desincentivadas por poderem acarretar em competição intraespecífica (Modesto Júnior et al. 2019). Esse modelo técnico-científico é bem conhecido pelos moradores da comunidade, uma vez que eles participam de cursos e seminários governamentais que têm o intuito de trazer esse conhecimento para as comunidades rurais. Porém, essa não é a forma que Maria escolhe plantar.

Durante as observações realizadas, Maria foi questionada quanto à distância entre as covas que ela estava cavando com a enxada, para enterrar a maniva e o fertilizante. A nota etnográfica abaixo descreve sua resposta:

Perguntei a Maria por que as covas foram cavadas tão perto uma da outra e se essa era a recomendação. Ela pegou a enxada, colocando-a em uma posição horizontal logo acima do solo, e disse: "olha, isso é quase 1 metro, olha todo o espaço que a gente ia perder se fosse pra plantar do jeito que eles recomendam".

A forma como Maria respondeu a esse questionamento é instrutivo para nossa análise. Primeiramente, ela fez uso do sistema métrico quando falou sobre a recomendação técnica (1 metro), mesmo resistindo em colocar o espaçamento que ela utiliza nessa unidade. Além disso, ela incluiu a enxada na assembleia de entidades que constituem seu dispositivo de medição, o que permitiu que essa comparação entre espaçamentos fosse realizada na prática, não em abstrato. Ou seja, Maria optou por não traduzir a sua prática de saber para uma linguagem não corporificada (por exemplo: "eu planto mandioca com espaçamento de $30 \mathrm{~cm}$, o recomendado é 1 metro"). Ao invés disso, ela materializou a recomendação abstrata em sua enxada, corporificando e contextualizando essa medida.

Esse encontro entre saberes conflitantes indica uma possível estratégia utilizada por Maria para resistir que sua prática tradicional seja submetida ao método recomendado. Como mencionado acima, para resolver essa contradição existe a necessidade de tornar ambas 
medidas comensuráveis. No entanto, a linguagem abstrata não foi escolhida por Maria como o espaço onde essa comensurabilidade seria atingida, mas sim o campo material da roça, na qual essa medida é inseparável de todas as outras entidades presentes. Ali, nessa assembleia heterogênea, a reflexão sobre o espaço que seria perdido se torna coerente, e o saber local mais forte que o científico.

Essa análise exemplifica a não neutralidade da criação de comensurabilidade (Stengers 2011): da mesma forma que a comparação realizada por Maria não foi uma atividade imparcial, o mesmo se aplica para o oposto, a imposição de uma linguagem abstrata e descontextualizada sobre os saberes tradicionais. Dessa forma, a não utilização do sistema métrico ganha uma nova camada de complexidade, uma vez que pode ser entendida como parte de um mecanismo de resistência do saber local da comunidade Espírito Santo do Itá.

\section{Pé com ponta e relevância semiótica material}

O conflito entre práticas de saber não consiste somente de ataques do saber técnico-científico ao saber local, e este segundo não é uma entidade passiva. Quando uma comensurabilidade é estabelecida, certos critérios precisam ser definidos como relevantes, e eles carregam consigo uma parcialidade que podem determinar essas negociações. Aqui, investigamos a definição dessas relevâncias.

Em uma conversa informal enquanto Maria plantava as manivas, ela contou uma história de quando uma mulher visitou a comunidade para ensiná-los algumas coisas técnicas sobre a agricultura. Maria explicou: "ela ensinou muitas coisas pra a gente. Mas quando ela terminou eu falei que tinha uma pergunta pra ela: 'de qual lado da maniva que sai a raiz?'. Ela disse que não sabia, daí eu falei: 'Você ensinou coisas pra a gente, e agora eu vou ensinar uma coisa pra você”.

Um episódio similar foi contado por Sr. Aleontino (Pai de Maria) e Sr. André, quando foram perguntados o motivo para eles continuarem plantando mandioca por tanto tempo. Sr. Aleontino disse: "O porque eu não sei, mas o que eu tenho certeza é que mandioca é o que 
eu sei como plantar.” Ele continuou explicando que a geração mais nova não sabe mais como plantar a mandioca direito: "Você tem que botar pé com ponta! Muita gente não sabe disso" (Sr. Aleontino, em entrevista).

Na comunidade, diferenciar os lados da maniva é relevante, tanto simbolicamente, quanto materialmente: é um conhecimento central para a prática de saber ali presente. $\mathrm{O}$ mesmo não é verdade em relação aos textos técnicos: os lados da maniva não parecem ser considerados uma informação relevante para o plantio, principalmente já que: "[...] recomenda-se que apenas uma maniva seja usada em cada cova. [...] [plantar mais de uma maniva] causa um desperdício de material de plantio e produz plantas multicaule, que são menos eficientes" 10 (Lebot 2009:53-4 - tradução nossa).

Plantar 'pé com ponta' é tradicionalmente considerada como a forma mais eficaz de se plantar mandioca na comunidade. Sr. Aleontino explicou que se for feito dessa forma, "[...] você vai plantar uma tarefa e colher duas". Maria explicou o benefício dessa prática de outra forma: "[...] se uma falhar, a outra dá. No caso, se morrer uma, a outra nasce”. Apesar dessas posições, em sua narrativa, Maria não traça uma comparação quanto a eficácia da forma como a comunidade planta e das recomendações pela palestrante. Ao invés disso, ela desafia a representante do conhecimento técnico sobre seu saber íntimo da raiz. O questionamento de Maria, por si só, não explicita a relação entre saber distinguir os lados da maniva e a função prática deste conhecimento na forma de plantar da comunidade; a questão é a ausência dessa relação íntima com a raiz no conhecimento técnico-científico.

A forma como esta comparação é construída por Maria possibilita duas reflexões pertinentes. Primeiramente, as práticas de saberes são colocadas como comensuráveis, mas o critério usado na comparação diz respeito a um conhecimento íntimo da raiz que, apesar de irrelevante para o modelo técnico-científico do plantio, é de grande importância para a prática tradicional. Em segundo lugar, o vínculo estreito dos membros da comunidade com essa raiz parece representar 
não somente um motivo de orgulho, como também uma possível ferramenta de resistência em relações conflituosas com práticas de saber divergentes. Naquele espaço, as pessoas são especialistas nesse saber material, corporificado e íntimo.

Essa relação entre a comunidade e a raiz pode, talvez, ser pensada como uma relação de 'espécies companheiras' (Haraway 2003; 2008). Donna Haraway explica que:

"[...] todos os atores tornam-se quem são na dança do relacionar-se, não do zero, não ex nihil, mas cheios dos padrões de suas heranças às vezes unidas, às vezes separadas, antes e paralelamente a este encontro. Todos os dançarinos são refeitos através dos padrões que eles performam"11 (Haraway 2008:25 - tradução nossa).

Em Espírito Santo do Itá, argumentamos, então, que essa relação semiótica-material íntima entre os quilombolas e essa mandioca forma e transforma tanto os membros da comunidade quanto a raiz. Em outras palavras, essas entidades 'intra-agem' (Barad 2007). Como explica Barad: "É através de intra-ações agenciais específicas que as fronteiras e as propriedades dos 'componentes' dos fenômenos tornam-se determinadas e que particulares conceitos corporizados adquirem significado." (2017:20). A mandioca e os membros da comunidade não preexistem suas relações: a mandioca, assim como os quilombolas de Espírito Santo do Itá, depende dessa intra-ação.

\section{Idade do material de plantio e incomensurabilidades}

Essa última narrativa se diferencia das anteriores. Nos exemplos acima, os saberes divergentes se tornam comensuráveis. Adiante, ao contrário, essa comensurabilidade não é alcançada e a falta dela é utilizada como uma ferramenta na negociação entre os saberes.

Durante conversas informais nas casas de farinha da comunidade, muitos tópicos são discutidos, desde histórias, fofocas, até os planejamentos de compra e venda para as próximas semanas. A nota etnográfica abaixo foi escrita em 24 de outubro: 
$\mathrm{Na}$ casa de Farinha, enquanto algumas pessoas estavam trabalhando, Conceição, irmã de Maria, ajudava seu marido, Tolete, que trabalhava ali. Ela estava esperando a farinha terminar de ser escaldada, para peneirá-la. Enquanto isso, decidi perguntalhe sobre os cursos de agricultura e processamento de farinha que, conforme fui informado, ela havia participado. Quanto às diferenças entre as recomendações e o que era realizado ali, ela explicou que foram ensinadas poucas coisas que ela não sabia, mas que como o curso era focado no processamento industrial da farinha, muito do que foi dito não poderia ser aplicado na comunidade. Após alguns minutos, ela lembrou de uma recomendação que ela não sabia anteriormente: "Eles disseram que as manivas têm que ser colhidas em plantas que tenham de 8 a 10 meses, isso eu não sabia”. Na comunidade, o material de plantio é coletado somente no momento de colheita, em torno de um ano após ter sido plantado. Perguntei para Maria: "Então se você tivesse terra, você retiraria as manivas de acordo com as recomendações ou da maneira tradicional?". Ela respondeu: "Da forma que a gente faz aqui. É assim que a gente faz as coisas. Eles fazem de um jeito, a gente faz de outro."

Nessa narrativa, o desacordo entre essas práticas de saber não é resolvida por uma comparação, como nos casos anteriores, mas por recusar a comparação. Em sua resposta, Conceição tornou esses saberes incomensuráveis.

\section{Conclusão: padrões de in/comensurabilidade}

Com base na discussão apresentada aqui, propomos a seguinte observação: os membros da comunidade parecem articular suas práticas de saber com o modelo técnico-científico através da criação de padrões de in/comensurabilidade que permite a eles resisitir à imposição de modelos externos e limitações de suas práticas. Apresentamos, portanto, três formas, calcadas em observações etnográficas, pelas quais os membros da comunidade lidam com atritos entre saberes divergentes: 1. Realizando comparações somente no campo material e corporificado, não em abstrato; 2. Controlando os critérios de relevância de modo a destacar as partes do conhecimento tradicional que 
estão ausentes na prática científica; 3. Criando incomensurabilidade, tornando, assim, inviável a realização de comparações.

Esses exemplos emergem do campo empírico e, portanto, não têm a pretensão de ser exaustivos. Apesar disso, acreditamos que eles oferecem uma maneira de explorar a relação entre saberes divergentes que extrapola o campo epistemológico e rejeitam o dualismo de natureza/cultura. Observando a construção de in/comensurabilidades, as distinções entre entidades material e simbolicamente relevantes nessas práticas se dissolvem: só restam performances semiótica-materiais.

Os argumentos aqui apresentados podem ser lidos também como uma tentativa de entender melhor os processos de contradição e divergência entre práticas de saber afim de contribuir na construção de o que Stengers (2005) chama de 'ecologia de práticas'. A prática tradicional de cultivo estudada coexiste com um saber divergente, negociando sua existência nesse espaço contestado e resistindo uma imposição externa. Dessa forma, a criação de in/comensurabilidade observada parece seguir uma lógica de confluência, como descrita pelo autor quilombola Antônio Bispo dos Santos, regida pelo princípio de que "[...] nem tudo que se ajunta se mistura, ou seja, nada é igual." (Santos 2015:89).

Além disso, gostaríamos de lembrar o leitor que não houve neste artigo uma tentativa de apresentar de maneira totalizante a prática tradicional, ou técnica, do cultivo de mandioca, ou de compará-las em abstrato. Os contrastes apresentados aqui foram utilizados meramente para identificar divergências, reconhecidas pelos membros da comunidade, e examinar como elas são resolvidas por eles. Portanto, as contradições encontradas somente na literatura, mas que não habitam a comunidade, não foram incluídas na análise.

Por fim, é importante ressaltar dois pontos: 1. A atividade de criação de padrões de incomensurabilidade não é neutra, ela é uma atividade política e não-inocente (Haraway 1995; Stengers 2011); 2. Isso não significa que ela seja um resultado de planejamento 'racional', ou um efeito de uma causa única. Essa atividade também é um resultado 
de uma assembleia heterogênea de entidades, e, portanto, não seria coerente com a literatura em que este artigo se embasa isolar a complexidade do campo para identificar uma causa única. A questão é a criação de in/comensurabilidades como uma reação ao encontro de saberes discordantes e as contribuições dessa prática para a resistência do saber tradicional.

\section{Notas:}

1 Algumas casas de farinha possuem mais que um dono, mas a posse continua sendo pouco relevante para o uso, uma vez que elas são coletivamente usadas.

2 A importância da coletividade e solidariedade na produção quilombola é destacada por Morais (2003) e Santos (2015).

3 Silva \& Silva (2015), em seu estudo sobre a produção de farinha na Comunidade Santo Antônio do Piripindeua (Pará), identificaram relações de produção semelhantes, mas utilizam o conceito de 'dono da farinha'.

4 Texto original: "[...] a movement in social science which cultivates a set of sensibilities to practice, to process, to the weaves of materiality and narrative, to the irredeemably situated character of those weaves (its own included), to difference, and to the idea that there is no single machinery at work behind the complexities of the social."

5 Texto original: "[...] an effort to circumvent epistemology and its attendant language of representation in favour of an approach that addresses itself more directly to the composition of the world."

6 Esse trabalho de campo também foi utilizado na escrita da dissertação de Gabriel Graton Roman intitulada 'Performing Cassava: a material semiotic investigation of the cassava and quilombolas of Espírito Santo do Itá', defendida na Norwegian University of Life Sciences.

7 Texto original: "Situated knowledges are not merely about knowing/seeing from somewhere (as in having a perspective) but about taking account of how the specific prosthetic embodiment of the technologically enhanced visualizing apparatus matters to practices of knowing".

8 Texto original: "Amerindians in Brazil use cuttings 50-60 cm long in non-mechanized cropping systems, but in the same country, modern and mechanized farms use $15-20 \mathrm{~cm}$ cuttings in mechanical planters. The most suitable length of cutting is found to be $15-20 \mathrm{~cm}$ in Thailand, $20-25 \mathrm{~cm}$ in Malaysia, $25-30 \mathrm{~cm}$ in India and short cuttings are recommended in the Philippines for horizontal planting and longer cuttings for vertical planting".

9 Texto original: "[a]ll measurements depend on embodied choices of apparatus, conditions for defining and including some variables and excluding others, and historical practices of interpretation". 
10 Texto original: "[...] it is recommended that only one cutting be used at each planting hole. [...] [plating more than one cutting] causes a waste of planting material and produces multistem plants, which are less efficient".

11 Texto original: "[...] all the actors become who they are in the dance of relating, not from scratch, not ex nihilo, but full of the patterns of their sometimes-joined, sometimes-separated heritages both before and lateral to this encounter. All the dancers are redone through the patterns they enact."

\section{Referências:}

ASPERS, Patrik. 2015. "Performing ontology." Social Studies of Science, 45(3):449-453.

BARAD, Karen. 2007. Meeting the University Halfway: Quantum Physics and the Entanglement of Matter and Meaning. Durham: Duke University Press. . 2014. "Invertebrate Visions: diffractions of the brittlestar". In KIRKSEY, E. (ed.): The Multispecies Salon, pp. 221-241. Durham: Duke University Press. . 2017. "Performatividade pós-humanista: para entender como a matéria chega à matéria." Vazantes, 1(1):7-34.

CALLON, Michel. 1980. "Struggles and negotiations to define what is problematic and what is not; the socio-logic of translation." In KNORR, K. et al. (eds): The Social Process of Scientific Investigation. Sociology of the Sciences Yearbook Vol. 4, pp. 197-219. Dordrecht: Reidel Publishing Company. 1984. "Some Elements of a Sociology of Translation: Domestication of the Scallops and the Fishermen of St Brieuc Bay." The Sociological Review, 32(1):196-233.

CASCUDO, Luís C. 2011. História da alimentação no Brasil. São Paulo: Global.

COSTA, Marcilene. 2010. Práticas alimentares em uma comunidade quilombola da Amazônia brasilleira. Trabalho apresentado no Seminário "Independências - Dependências - Interdependências" VI Congresso CEISAL, Toulouse, France.

.2012. "Mandioca é coida de quilombola? Representações e práticas alimentares em uma comunidade quilombola da Amazônia brasileira.” Amazônica-Revista de Antropologia, 3(2):408-428.

CUSSINS, Charis. 1996. "Ontological choreography: Agency through objectification in infertility clinics." Social Studies of Science, 26(3):575-610.

DANTAS, J. et al. 1981. Cultivo da Mandioca. Cruz das Almas, BA: Embrapa, CNPMF.

FURLANETO, F., KANTHACK, R. \& ESPERANCINI, M. 2007. "Análise econômica da cultura da mandioca no médio Paranapanema, estado de São Paulo." Informações Econômicas, 37(10):20-26.

GAD, C. \& JENSEN, C. 2010. “On the Consequences of Post-ANT." Science, Technology, $\mathcal{E}$ Human Values, 36(5):55-80 
GOMES, Flávio S. 2015. Mocambos e Quilombos: Uma História do campesinato negro no Brasil. São Paulo: Companhia das Letras.

HARAWAY, Donna. 1991. Simians, cyborgs, and women: The reinvention of nature. New York: Routledge. . 1995. "Saberes localizados: a questão da ciência para o feminismo e o privilégio da perspectiva parcial." Cadernos Pagu, 5:7-41.

2003. The companion species manifesto: Dogs, people, and significant otherness. Chicago: Prickly Paradigm Press.

2008. When Species Meet. Minneapolis and London: University of Minneapolis Press.

HOLBRAAD, M. \& PEDERSEN, M. 2017. The ontological turn: an anthropological exposition. Cambridge: Cambridge University Press.

HOLBRAAD, M., PEDERSEN, M. \& VIVEIROS DE CASTRO, E. 2014. "The Politics of Ontology: Anthropological Positions". Cultural Anthropology Online. (http://culanth.org/fieldsights/462-the-politics-of-ontologyanthropologicalposition; acesso em 20/04/20)

JENSEN, C. \& MORITA, A. (eds.). 2019. Multiple Nature-Cultures, Diverse Anthropologies (Vol. 9). New York: Berghahn Books.

JENSEN, C. \& RÖDJE, Kj. (eds.). 2010. Deleuzian intersections: Science, technology, anthropology. New York: Berghahn Books.

KOHN Eduardo. 2007. "How dogs dream: Amazonian natures and the politics of transspecies engagement." American Ethnologist, 34(1):3-24

LATOUR, Bruno. 1987. Science in action: How to follow scientists and engineers through society. Cambridge: Harvard University Press. 1993. We have never been modern. Cambridge: Harvard University Press. . 1996. "On actor-network theory: A few clarifications." Soziale welt, $47(4): 369-381$.

2005. Reassembling the Social: An Introduction to Actor-Network-Theory. Oxford: Oxford University Press.

LATOUR, B. \& WOOLGAR, S. 1986. Laboratory life: The construction of scientific facts. Princeton: Princeton University Press.

LAW, John. 1986. "On the Methods of Long Distance Control: Vessels, Navigation and the Portuguese Route to India." In LAW, J. (ed.): Power, Action and Belief: a new Sociology of Knowledge? Sociological Review Monograph, 32, pp. 234-263. London: Routledge and Kegan Paul.

LAW, John. 2019. Material Semiotics. (http://www.heterogeneities.net/ publications/Law2019MaterialSemiotics.pdf; acesso em 20/04/20).

LAW, J. \& LIEN, M. 2013. "Slippery: Field notes in empirical ontology." Social Studies of Science, 43(3):363-378.

LEBOT Vincent. 2009. Tropical root and tuber crops: cassava, sweet potatoes, yams and aroids. Wallingford, UK: CABI. 
MATTOS, P., FARIAS, A. \& FERREIRA FILHO, J. R. 2006. Mandioca: o produtor pergunta, a Embrapa responde. Brasília: Embrapa Mandioca e Fruticultura.

MODESTO JÚNIOR, M. \& ALVES, R. 2015. "Produção de farinha de mandioca e de farinha de tapioca no estado do pará como oportunidades de negócios para empreendedores e agricultores na amazônia." In DENARDIN, V. \& KOMARCHESKI, R. (eds.): Farinheiras do Brasil: tradição, cultura e perspectivas da produção familiar de farinha de mandioca, pp. 147-173. Matinhos: UFPR Litoral.

MODESTO JÚNIOR, M. S. et al. 2019. Sistema de produção de mandioca da comunidade quilombola de Gurupá, Pará. Belém: Embrapa Amazônia Oriental.

MOL, Annemarie. 2002. The Body Multiple: Ontology in Medical Practice. Durham: Duke University Press.

2013. "Mind your plate! The ontonorms of Dutch dieting." Social Studies of Science, 43(3):379-396.

MORAIS, Glória. 2003. "Para uma possível etnografia da comunidade do Pêga (Portalegre/RN)." Revista de Humanidades, 4(8):164-182.

BEZERRA NETO, J. M. \& MACÊDO, S. 2009. "A quitanda de joana e outras histórias: os escravos e as práticas alimentares na Amazônia (séc. XIX)". Histórica - Revista Eletrônica do Arquivo Público do Estado de São Paulo, 38:1-9.

O’DWYER, E. \& CARVALHO, J. P. 2002. “Jamary dos Pretos, município de Turiaçu (MA).” In O'DWYER, E. (ed.): Quilombos: identidade étnica e territorialidade, pp. 173-212. Rio de Janeiro: Editora FGV

OLIVEIRA, Osvaldo M. 2002. "Quilombo do Laudêncio, município de São Mateus (ES).” In O'DWYER, E. (ed.): Quilombos: identidade étnica e territorialidade, pp. 141-172. Rio de Janeiro: Editora FGV.

OMURA, K. et al. 2018. The World Multiple: The Quotidian Politics of Knowing and Generating Entangled Worlds. London/ New York: Routledge.

PEDROSO JUNIOR, N., MURRIETA, R. \& ADAMS, C. 2008. "A agricultura de corte e queima: um sistema em transformação." Boletim do Museu Paraense Emílio Goeldi, 3(2):153-174.

SANTOS, Antônio Bispo dos. 2015. Colonização, quilombos: modos e significações. Brasília: Instituto de Inclusão no Ensino Superior e na Pesquisa.

SILVA, C. \& SILVA, M. G. 2015. "Casas de farinha: cenários de (con)vivências, saberes e práticas educativas." In DENARDIN, V. \& KOMARCHESKI, R. (eds.): Farinheiras do Brasil: tradição, cultura e perspectivas da produção familiar de farinha de mandioca, pp. 56-81. Matinhos: UFPR Litoral.

STAR, S. \& GRIESEMER, J. 1989. "Institutional ecology, 'translations' and boundary objects: amateurs and professionals in Berkeley's Museum of Vertebrate Zoology, 1907-39.” Social Studies of Science, 19(3):387-420.

STENGERS, Isabelle. 2005. "Introductory notes on an ecology of practices". Cultural Studies Review, 11(1):183-196.

STENGERS, Isabelle. 2011. "Comparison as a matter of concern." Common Knowledge, 17(1):48-63. 
VAN HEUR, B., LEYDESDORFF, L. \& WYATT, S. 2013. "Turning to ontology in STS? Turning to STS through 'ontology'." Social Studies of Science, 43(3):341-362.

VIANA, A. et al. 2000. "Effects of length in stem cutting and its planting position on cassava yield." Acta Scientiarum, 22(4):1011-1015.

VIZOLLI, I., SANTOS, R. \& MACHADO, R. 2012. "Saberes Quilombolas: um estudo no processo de produção da farinha de mandioca." Bolema, 26(42B):589-608.

WOOLGAR, S. \& LEZAUN, J. 2013. "The Wrong Bin Bag: A Turn to Ontology in Science and Technology Studies?". Social Studies of Science, 43(3):321-340. . 2015. "Missing the (question) mark? What is a turn to ontology?". Social Studies of Science, 45(3):462-467.

\begin{abstract}
This article examines the way cassava is planted in the Quilombola Community Espírito Santo do Itá (PA) in order to identify moments of conflict and negotiations between the traditional knowledge, materialized in the practice of local cultivation, and the technical-scientific one, introduced mainly through technical courses offered to producers in the community. The cultivation practices are examined following a material semiotic approach, thus moving beyond a purely epistemological discussion, making knowledge also an ontological matter. In the ethnographic moments explored, three strategies used in the community that contribute to the coexistence of local knowledge in the face of divergent technical-scientific knowledge were identified: 1 . The performance of comparisons in the material and bodily field; 2 . The control of the relevant criteria for comparisons; and 3. The creation of incommensurability. Thus, we suggest that the negotiation between divergent knowledge-practices in the community is marked by articulations of patterns of in/commensurabilities.
\end{abstract}

Keywords: Material semiotics, Local knowledge, Knowledge practices, Commensurability, Quilombola. 